\title{
FEEDING SYSTEM OF AEROSTATIC BEARINGS WITH POROUS MEDIA
}

\author{
Guido BELFORTE, Terenziano RAPARELLI, Vladimir VIKTOROV, Andrea TRIVELLA \\ Department of Mechanics, Politecnico di Torino, Technological University \\ C.so Duca degli Abruzzi, 24 - 10129 - Torino -Italy \\ (E-mail: raparelli@polito.it)
}

\begin{abstract}
This study is an experimental investigation on porous media in feeding system of aerostatic bearings. The experiments were conducted using sintered bronze cylindrical inserts of different length, diameter and particle size. The work outlines two types of experiments namely: a) the measurement of mass flow rate through single porous resistance with different upstream and downstream pressures; b) the study of pressure distribution, on a pneumatic pad featuring porous resistance feeding system. The set-up used for the former included the device under test, a flow regulator and pressure transducers. For the latter the set-up included the pad under test and a stationary bearing member under the pad to evaluate pressure distribution by means of a pressure transducer.

The immediate objective of the work is to define a fluid porous resistance to be provided on the pad, equivalent to that of a $0.25 \mathrm{~mm}$ calibrated orifice already applied to a similar pad.
\end{abstract}

\section{KEY WORDS}

Air feeding systems, Porous media, Forchheimer law

\section{NOMENCLATURE}

$D: \quad$ Nominal porous resistance diameter

$D_{p}: \quad$ Average particle diameter

$L: \quad$ Nominal resistance length

$G$ : $\quad$ Mass flow rate

$P$ : $\quad$ Absolute pressure under the pad

$P_{1}$ : $\quad$ Upstream insert absolute pressure

$P_{2}$ : $\quad$ Downstream insert absolute pressure

$P_{S}: \quad$ Absolute supply pad pressure

$V: \quad$ Volume of porous resistance

$d: \quad$ Diameter of calibrated orifice $l: \quad$ Length of calibrated orifice

$h: \quad$ Air gap

$m: \quad$ Mass of porous resistance

$r: \quad$ Radial coordinate

$\delta$ : $\quad$ Pocket depth

$\gamma: \quad$ Density of bronze

$\phi$ : $\quad$ Porosity

\section{INTRODUCTION}

In air devices, concentrated resistances normally consist of calibrated orifices of suitable diameter and length. The 
precision required creates problems which at times are difficult to solve, especially for diameters smaller than 0.1 to $0.2 \mathrm{~mm}$ which are also easily clogged. To minimise the problem sintered resistance inserts of suitable shape may be used.

The performance of porous resistances has been the subject of intensive study. Porous resistances may be regarded as an array of multiple tortuous ports resembling many tiny parallel-connected resistances. In terms of laminar flow they may be described as adhering to the Darcy law, and for the higher Reynolds numbers a modified Forchheimer law would apply [1] - [7].

Although basic studies are long established, research has recently aroused widespread interest in this area, as shown for instance by the rich bibliography on applications such as feeding systems for air bearings. Results obtained indicate that careful resistance design may bring benefits in terms of load, stiffness and damping of air bearings [8] - [15]. Material porosity may be achieved in various ways, from conventional metal powder sintering to the more recent laser drilling after surface densification by mechanical rolling and use of porous plastics. In all cases the parameter which is critical for porous resistance bearings is the permeability of the material, which in turn is highly dependent on the type of process selected for achieving porosity.

This work investigates sintered bronze porous resistances having conductance similar to that of a 0.25 $\mathrm{mm}$ dia., $0.5 \mathrm{~mm}$ deep calibrated orifice. A number of specimens of different particle size and dimensions were flow tested. Subsequently, we studied the behaviour of an air pad in which the calibrated orifice is replaced with interchangeable porous resistances. Results obtained in terms of pressure distribution and air consumption are useful for evaluating output coefficients [17 - 18].

\section{POROUS DEVICES TESTED}

As resistance material we selected three types of commercial bronze powders of different grain size. Powder consists of $89 \%$ copper, $11 \%$ tin and is globular in shape. Average diameter $D_{p}$ for each grain size was obtained from a statistical sample 200 granules. Diameters for the three types are $114 \mu \mathrm{m}, 66 \mu \mathrm{m}$ and $52 \mu \mathrm{m}$ respectively. Figures 1,2 and 3 show magnified views of the three powders. Powders were sintered in cylindrical dies at $780^{\circ} \mathrm{C}$ for 130 minutes. Test specimen size is nominal dia. $D=3 \mathrm{~mm}$ by nominal length $L=3 \mathrm{~mm}$ or $L=$ $5 \mathrm{~mm}$. Many specimens were produced in order to verify repeatability of experimental results for each type of resistance. Shrinkage of sintered material caused dimensional changes relative to nominal size. Table 1 shows the various types of resistances tested and actual average sizes.

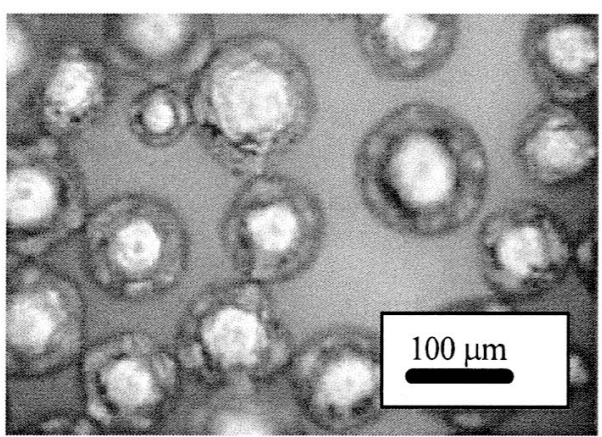

Figure 1: Powder particle size $D_{p}=114 \mu \mathrm{m}$

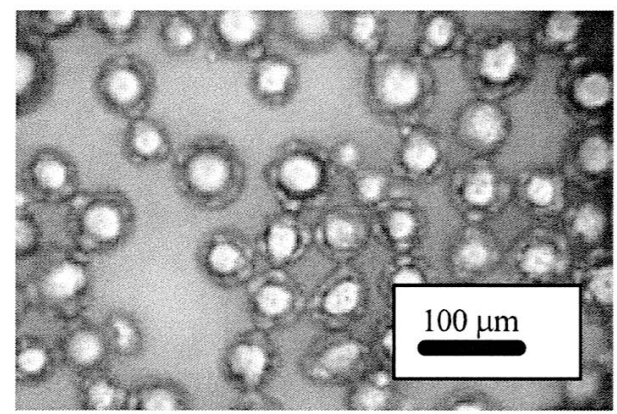

Figure 2: Powder particle size $D_{p}=66 \mu \mathrm{m}$

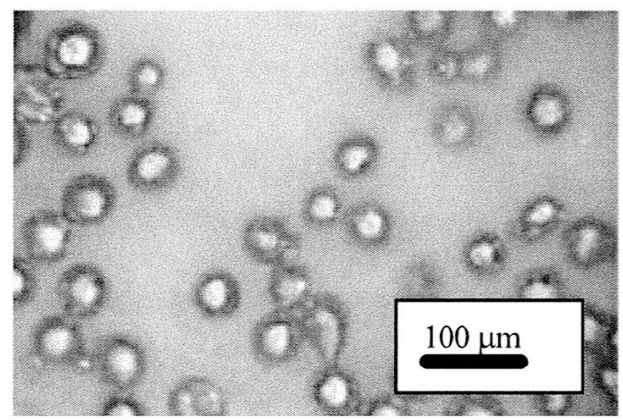

Figure 3: Powder particle size $D_{p}=52 \mu \mathrm{m}$

Figure 4 illustrates a macroscopy of porous resistances " $c$ " and " $d$ "; figures 5, 6 and 7 show magnified base surfaces of resistances obtained with the three different grain sizes. Note how particle size is smaller than that of untreated powder due to linking effect of sintering.

Table 1: Dimensions and particle size of porous resistances

$\begin{array}{cccccc}\begin{array}{c}\text { Resistance } \\ \text { Ref. }\end{array} & D & D_{\text {eff }} & L & L_{\text {eff }} & D_{p} \\ & & & & & \\ a & 3 \mathrm{~mm}] & {[\mathrm{mm}]} & {[\mathrm{mm}]} & {[\mathrm{mm}]} & {[\mu \mathrm{m}]} \\ b & 3 & 2.93 & 3 & 2.81 & 114 \\ c & 3 & 2.94 & 5 & 4.69 & 114 \\ d & 3 & 2.95 & 5 & 4.60 & 66 \\ e & 3 & 2.86 & 3 & 2.74 & 52 \\ f & 3 & 2.91 & 5 & 4.57 & 52\end{array}$




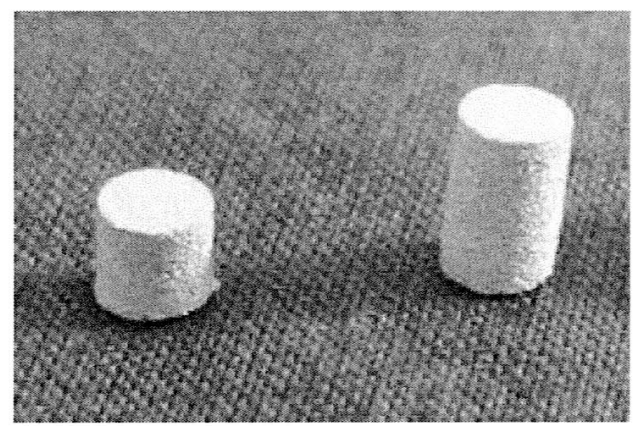

Figure 4: Photo of resistances " $c$ " and " $d$ "

Actual porosity is the ratio of fluid flow active volume to resistance total volume. Total porosity is the ratio of volume of all voids of the resistance to total volume. Actual or effective porosity is more significant than the latter, as some voids may well be impossible to be penetrated by the fluid. However, total porosity provides a quick indication of material porosity through assessment of dimensions and sintered mass in relation to density of material. Actual porosity is lower than total porosity as per suitable correction factors.

Total porosity $\Phi$ is:

$$
\Phi=1-\frac{m}{\gamma \cdot V}
$$

where $\gamma=8.74 \cdot 10^{3} \mathrm{~kg} / \mathrm{m}^{3}$ is the density of bronze 89 $11, m$ is the mass of porous resistance and $V$ is the total volume. Tests conducted for each grain size on several specimens of different lengths have yielded the average values given in Table 2:

Table 2: Average values of porosity

$\begin{array}{ccc}\begin{array}{c}\text { Resistance } \\ \text { Ref. }\end{array} & D_{p}[\mu m] & \Phi \\ a, b & 114 & 0.351 \\ c, d & 66 & 0.334 \\ e, f & 52 & 0.294\end{array}$

\section{MONITORING OUTPUT CHARACTERISTICS}

Two types of tests were conducted using specific setups.

\section{a) Porous resistance fl ow test}

Figure 8 shows the set-up produced for this test. Each porous resistance (1) was adhesive bonded to a metal sleeve (2) to seal possible leakage between specimen side face and sleeve. Owing to the difficulty of achieving good repeatability of resistance-to-sleeve bond, resistance effectiveness may vary, often considerably, among different specimens of the same type.

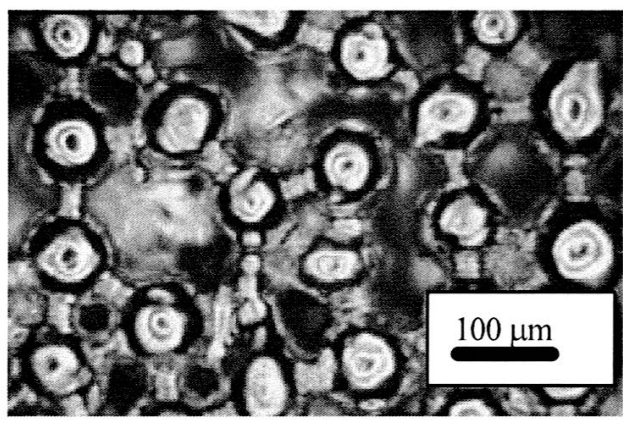

Figure 5: Magnified sintered powder particle size $D_{p}=114 \mu \mathrm{m}$

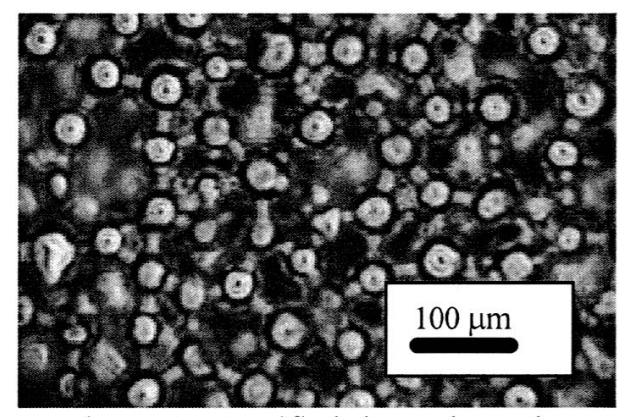

Figure 6: Magnified sintered powder particle size $D_{p}=66 \mu \mathrm{m}$

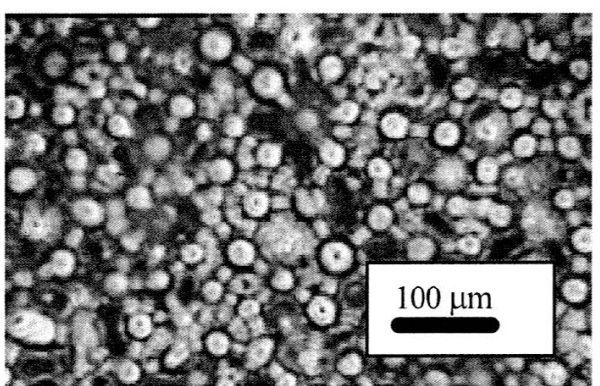

Figure 7: Magnified sintered powder particle size $D_{p}=52 \mu \mathrm{m}$

To overcome the problem, bonding tests were carried out using different specimens of the same type until satisfactory flow reading repeatability was obtained. Subsequently, six porous resistances as shown in Table 1 were fitted to six sleeves. All sleeves are of equal geometry and size so as to be interchangeable in the flow test device. Each sleeve is installed between flanges (3) and (4) connecting air inlet and outlet tubing. Flanges incorporate test ports for pressure $P_{I}$ and pressure $P_{2}$ upstream and downstream of resistance under test. Resistance inlet incorporates high-efficiency air filters (5) and pressure regulator (6), resistance outlet 
is provided with variable resistance (7) and flowmeter (8). Figure 9 shows a resistance in position inside sleeve.

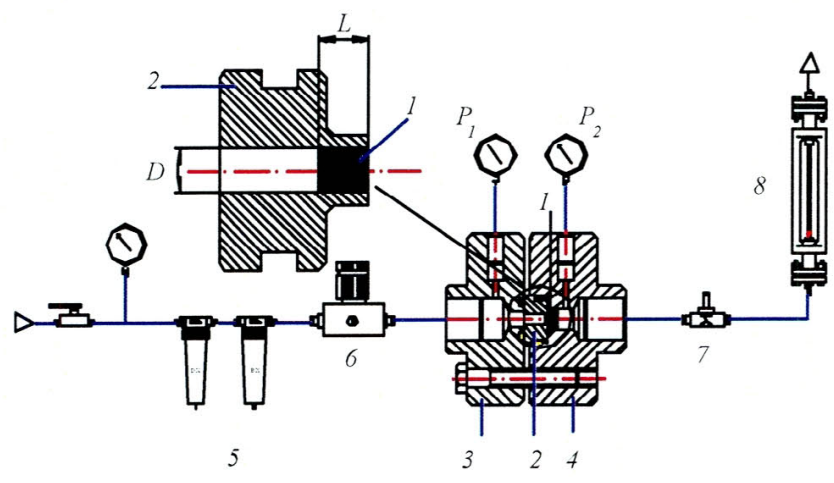

Figure 8: Test set-up for single porous resistance

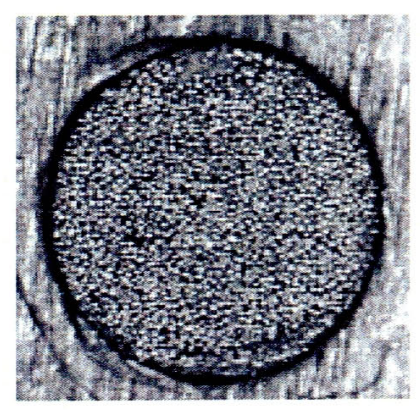

Figure 9: Illustration of resistance " $a$ " bonded to sleeve

Figures 10, 11 and 12 show results of all resistances tested. Unbroken lines represent $L=3 \mathrm{~mm}$, broken lines represent $L=5 \mathrm{~mm}$.

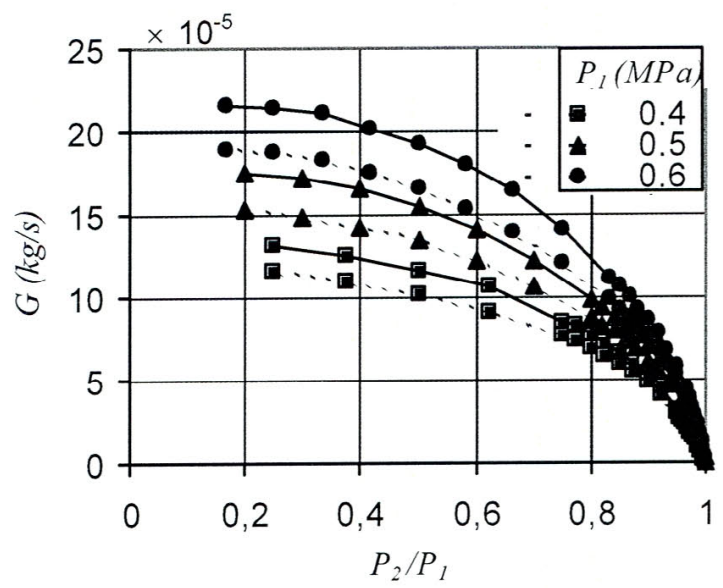

Figure 10 : Flow rates of inserts " $a$ " (unbroken lines), and for inserts " $b$ " (broken lines)

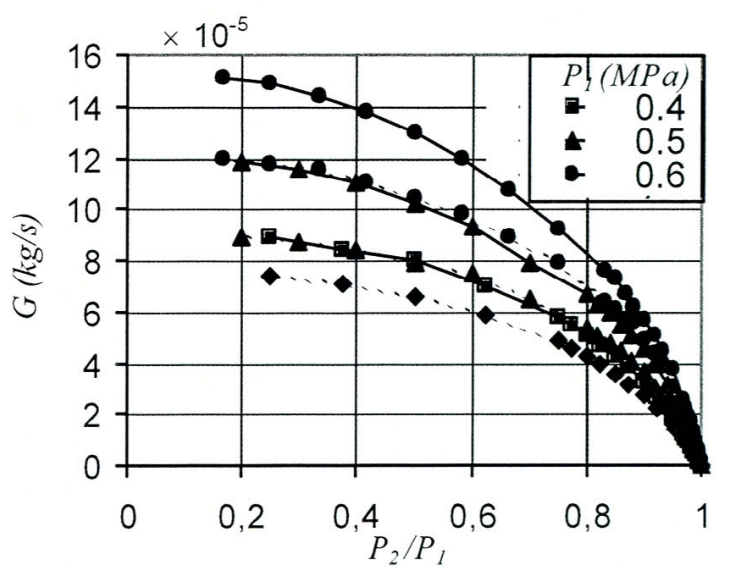

Figure 11 : Flow rates of inserts " $c$ " (unbroken lines), and for inserts " $d$ " (broken lines)

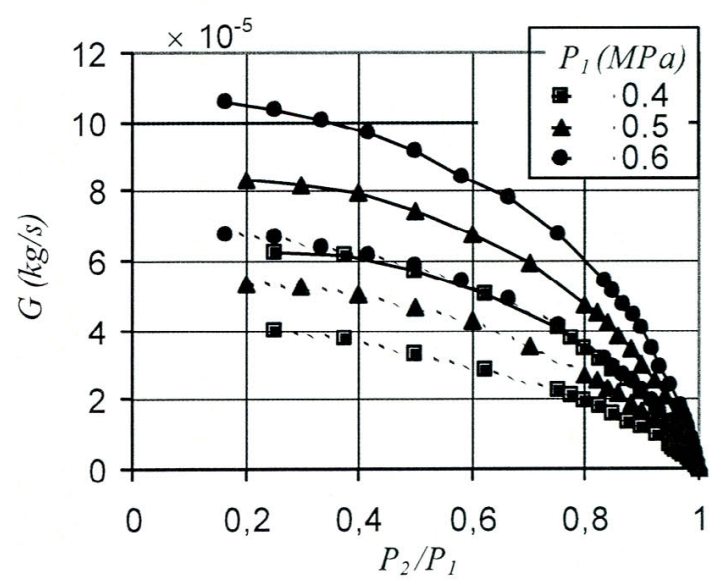

Figure 12 : Flow rates of inserts " $e$ " (unbroken lines), and for inserts " $f$ " (broken lines)

For the sake of comparison, Figure 13 shows flow characteristic of $d=0.25 \mathrm{~mm}$ dia., $l=0.5 \mathrm{~mm}$ deep calibrated orifice.

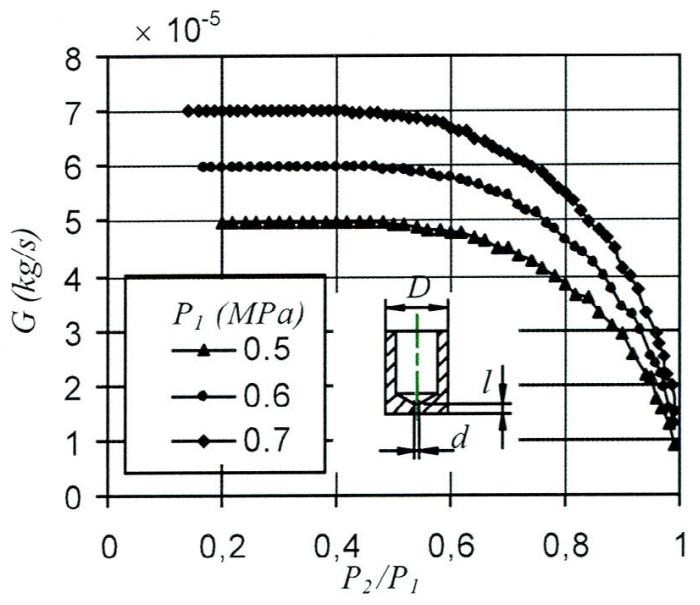

Figure 13: Flow rate readings for $d=0.25 \mathrm{~mm}, l=0.5 \mathrm{~mm}$ calibrated orifice. 
It can be seen that the resistance " $f$ " shows a behavior similar to that of the calibrated orifice. Note that for porous resistances and for $P_{2} / P_{1}$ readings approaching one, curves are more linear than that of calibrated orifice. For lower $P_{2} / P_{1}$ readings curves tend to become parabolic. This behaviour may be explained by the Darcy - Forchheimer relation [1-7] which considers both the effects of laminar flow for small pressure differentials upstream to downstream of porous resistance, and the effects of turbulent flow for greater pressure drops.

\section{b) Opposed pad test}

A thrust air pad incorporating porous resistances was tested to evaluate pressure distribution. The pad, shown in Figure 14, is cylindrical in shape and permits the installation of sleeves described above. Thus, individually tested specimens could be installed in the pad, thereby obtaining a direct comparison of flow rate readings with and without opposed pad in order to avoid repeatability problems due to adhesive bonding conditions.

A test set-up [17] was constructed for evaluating static load capacity, pressure distribution and air consumption of flat aerostatic pads with supply systems of this type as a function of air gap. Figure 15 shows the layout of pad set-up. The set-up frame consists of a base (1), three columns (2) and a crossmember (3). The air gap is provided between pad under test (4) and stationary bearing member (5). Pad (4) can move vertically by means of screw (6) and handwheel (7). Depth of air gap is monitored by three micrometer transducers (8) resting on plate (9) connected to the pad. Thrust on the pad is monitored by load cell (10).

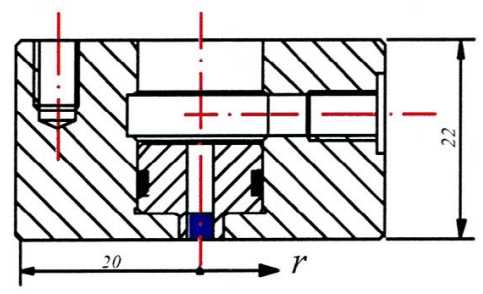

Figure 14: Pad under test

Figure 16 shows detail of central area of pad (4) and stationary bearing member (5), parallel faces thereof being spaced at a distance $h$. Porous resistance (1) and sleeve (2) are clearly visible. Sleeve profiles are offset internally relative to pad by the amount $s$. Each porous resistance examined is internal to sleeve profile at a depth $\delta$ which varies case by case. Moreover, owing to the nature of the sintered material, outer profile of resistance is not consistent; in fact it varies significantly in radial direction $r$, and in circumferential direction $\theta$.

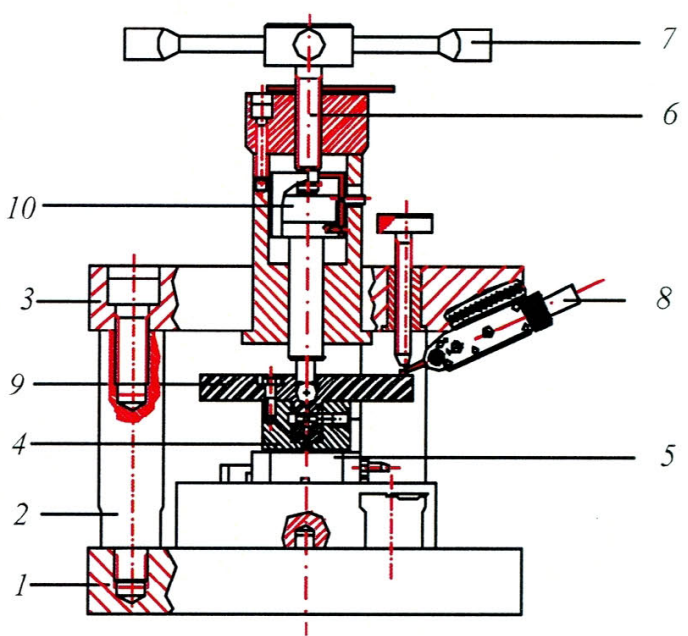

Figure 15: Pad test set-up

Table 3 shows actual average specimen depth $\delta_{n}$, max. depth change $\Delta \delta$ and the value of $s$ for the six test specimens.

Tests were conducted on all resistances at pad feed pressure $P_{S}=0.4,0.5$ and $0.6 \mathrm{MPa}$, for gap size $h=9$ and $14 \mu \mathrm{m}$. As an example, Figure 17 shows the pattern of radial distribution of pad pressure for resistance " $f$ " at feed pressure $P_{S}=0.6 \mathrm{MPa}$.

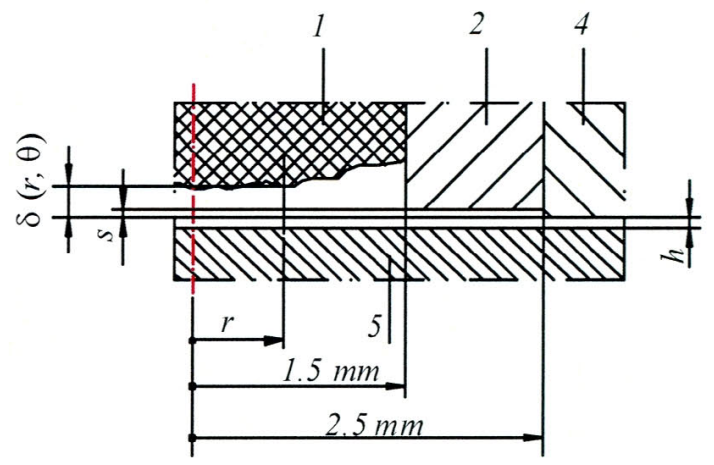

Figure 16: Center area of pad and stationary bearing member

Table 3: Average depth of resistance profile from edge of pad $\delta_{n}$, max. change thereof $\Delta \delta$, and $s$

$\begin{array}{cccc}\begin{array}{c}\text { Resistance } \\ \text { Ref. }\end{array} & \begin{array}{c}\delta_{n 1} \\ {[\mu m]}\end{array} & \begin{array}{c}\Delta \delta \\ {[\mu \mathrm{m}]}\end{array} & \begin{array}{c}s \\ {[\mu \mathrm{m}]}\end{array} \\ a & 170 & 25 & 34 \\ b & 118 & 18 & 10 \\ c & 140 & 20 & 23 \\ d & 501 & 15 & 22 \\ e & 340 & 22 & 15 \\ f & 205 & 26 & 22\end{array}$




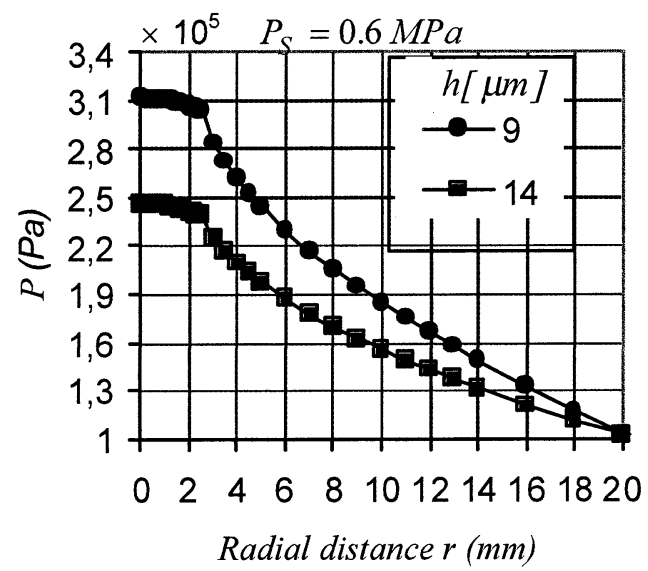

Figure 17. Example of radial absolute pressure distribution across pad with resistance " $f$ "

\section{CONCLUSIONS}

Experimental investigation of porous inserts has yielded solutions for replacing fluid resistances with concentrated orifices.

Test methods and equipment have been developed for evaluating fluidic behaviour of porous resistances.

These porous resistances can also be utilized in pneumatic valves.

Characterization testing of porous resistances according to the Darcy-Forchheimer laws is currently in progress. The results of this work will be the subject of a future paper.

\section{REFERENCES}

1. A.E. Scheidegger. The physics of flow through porous media, University of Toronto press. 1963.

2. De Wiest. Flow through porous media. Academic Press, New York, 1969.

3. F.A.L. Dullien. Porous Media, fluid transport and pore structure. Academic Press, 1979.

4. G. S. Beavers, E.M. Sparrow. Non-Darcy Flow through fibrous porous media. Journal of Applied Mechanics, Trans. ASME, December 1969, Vol. 36, pp. 711-714.

5. G. S. Beavers, E.M. Sparrow, D.E. Rodenz. Influence of bed size on the flow characteristics and porosity of randomly packed beds of spheres, Journal of Applied Mechanics, Trans. ASME, September 1973, pp.655-660.

6. Antonio Lorenzi. Laminar, turbulent and transition flow in porous media. Meccanica, Journal of the Italian Association of the Theoretical and Applied Mechanics, Vol. 10, N², June 1975, pp.75-77.
7. J.S. Andrade, U.M.S. Costa, M.P. Almeida, H.A. Makse, H.E. Stanley. Inertial effects on fluid flow through disordered porous media. Physical Review letters, Vol.82, $\mathrm{N}^{\circ}$ 26, June 1999, pp 5249-5252.

8. P.R.K. Murti. Analysis of externally pressurized gas porous bearings. Transactions of ASME, July 1974, pp. $354-360$

9. Y.B.P. Kwan, J. Corbett. Porous aerostatic bearings an updated rewiew. Wear, 1998, N²22, pp.69-73.

10. T.S. Loung, W. Potze, J.B. Post, R.A.J. van Ostayen, A.van Beek. Numerical and experimental analysis of aerostatic thrust bearings with porous restrictor. Tribology International, Vol. 37, 2004, pp.825-832.

11. A.H. Slocum. Precision Machine Design. PrenticeHall, $1^{\text {st }}$ edn., 1992.

12. Y. Tian, Modélisation statique et dynamique des paliers par la mèthode des elements finis et comparaison expérimentale. Thesis, 1991, UTC, Compiègne (French).

13. M. Fourka, M.Bonis. Comparison between externally pressurized thrust bearings with different orifice and porous feeding systems. Wear, 1997, $\mathrm{N}^{\circ} 210$, pp.311-317.

14. H. Rabia. Modélisation des paliers aérostatiques a paroi poreuse par la méthode des elements finis. Thesis, 1995, UTC, Compiègne (French).

15. J. Hopfner. Fertigung von aerostatischen lagern aus poroser sinterbronze mit oberflachenverdichteter drosselschicht. Thesis, 1990, UTM, Munchen.

16. Malik $\mathrm{M}$, Rodkiewicz $\mathrm{Cz} \mathrm{M}$. On the flow considerations in gas-lubricatedporous bearings. Transactions of the ASME, 1984, $\mathrm{N}^{\circ} 106$, pp. 484491.

17. G. Belforte, T. Raparelli, V.Viktorov, A. Trivella. Effects of supply hole dimensions and operating conditions on the hole discharge coefficient of an aerostatic bearing. $3^{\text {rd }}$ AIMETA International Tribology Conference, September 18-20, 2002, Vietri sul Mare, Salerno, Italy, cd rom ISBN 88-900908-0-4.

18. G. Belforte, T. Raparelli, V.Viktorov, A. Trivella. Discharge coefficients of simple orifices with feed pocket for aerostatic bearings. $4^{\text {th }}$ AIMETA International Tribology Conference, September 14 17, 2004, Rome, Italy, pp.467-474, cd rom ISBN 887999-831-5.

\section{ACKNOWLEDGEMENTS}

The authors would like to thank Marco Occhetto, Sandro Quaranta, Mihaela Tabacaru and Marius Botea for their help in conducting experimental tests. 